Doutora em Ciências Sociais (Antropologia) pela PUC-SP e professora do Programa de Pós-Graduação em Artes, Cultura e Linguagens do Instituto de Artes e Design da Universidade Federal de Juiz de Fora. Pesquisadora dos temas: juventude, cultura juvenil, moda contemporânea e moda juvenil.

E-mail:murilho@gmail.com

\title{
Juventude e moda em 0 grande Gatsby
}

\section{Youth and fashion in The great Gatsby}

[resumo] Tomando a moda como reflexo dos comportamentos sociais, o artigo pretende mostrar, a partir da obra O grande Gatsby, de Scott Fitzgerald, que na década de 1920 já havia uma cultura juvenil em esboço. Ainda que restrita a uma classe social específica, foi um período de aparente relaxamento do autocontrole e de maior hedonismo.

\section{[palavras-chave}

juventude; moda; cultura juvenil;

hedonismo.

[abstract] Assuming fashion as a reflex of social behavior, this article intends to show, based on the work of Scott Fitzgerald, The great Gatsby, that there was already a youth culture in sketch since the 1920s. Although restricted to a specific social class, it was a period of apparent self-control relaxation e and greater hedonism.

[keywords] youth; fashion; youth culture; hedonism. 
É curioso. Conhecemos o jovem há 40 mil anos. Digo "40 mil", como poderia dizer um milhão. Há um milhão de anos conhecíamos o jovem. A não ser o caso de um Goethe, aos dezessete anos, ou de um Rimbaud, aos dezessete anos, o jovem era um ser provisório, inacabado, que vivia, pelos cantos, gemendo de imaturidade. E o jovem só passava a existir, a ser levado em conta, quando deixava de ser jovem (RODRIGUES, 1996, p. 221).

Esse fragmento extraído de uma crônica de Nelson Rodrigues revela seu espanto diante das transformações culturais ocorridas ao final da década de 1960, principalmente no que se refere ao estatuto que a juventude passou a ter nas sociedades ocidentais. Antes desse momento, os jovens não eram suficientemente importantes para ser levados em conta, a subordinação econômica determinava uma subordinação social, e somente após sua independência econômica é que passavam a gozar de um status na sociedade. ${ }^{1}$ A expressividade demográfica e os avanços da indústria nos anos do pós-guerra fizeram dos adolescentes e jovens, primeiro, consumidores $e_{\text {, }}$ depois, sujeitos capazes de interferir nos rumos da história, como se viu nas décadas seguintes. A partir dos anos 1960, a juventude se tornou o momento mais valorizado da vida e, aos poucos, conseguiu impor seus valores para toda a sociedade, de maneira que todos os outros grupos etários (atualmente até as crianças) passaram a viver perseguindo esses ideais de beleza e desprendimento característicos desse período da vida. A possibilidade da educação prolongada, dos lazeres, da fruição de música e outros produtos culturais específicos, enfim, a condição juvenil, alargou-se nesse momento para uma massa, atingindo os jovens das camadas médias, tanto na Europa e Estados Unidos como também no Brasil, mesmo que em menor escala (GROPPO, 2000; SILVA, 2011).

Além da considerável expansão da indústria cultural a partir da música, dos filmes e das histórias em quadrinhos que eram produzidos tendo em vista esse público, também a indústria da moda contribuiu para marcar as diferenças entre as gerações. Se antes tecidos encorpados e uma modelagem rígida destacavam os atributos femininos ou masculinos nos corpos, a partir do final da década de 1950, as calças jeans, as camisetas, o encurtamento das saias, a aderência das malhas de algodão, tudo isso vai evidenciando a juventude dos corpos e confundindo os contornos dos gêneros. Em vez de expressar a classe social, como no modelo proposto por Simmel (2008) e observado no início do século $X X$, a moda da juventude passa a traduzir o pertencimento aos novos estilos culturais ou subculturais (LIPOVETSKY, 2004).

Outra grande mudança que a revolução juvenil trouxe para a sociedade foi um relativo relaxamento do autocontrole característico da civilização ocidental. Segundo Elias (1994), a civilização seria um longo processo de educação dos sentidos e das manifestações corporais mais naturais que o indivíduo foi aprendendo a reprimir e camuflar, ao longo dos séculos, tornando seus atos, de certo modo, ritualizados pelas boas maneiras. Como fruto desse processo longamente implantado nas sociedades ocidentais, aprendemos a conter as emoções como parte das regras de convivio em sociedade. Originalmente, a civilização seria a substituição de formas "naturais" de interação entre os indivíduos, das quais a violência não está excluída, por modos de convívio baseados no autocontrole. Isto é, na repressão de emoções e sentimentos espontâneos e na observância da etiqueta e da educação ao interagir com outros indivíduos.

No entanto, como a cultura das sociedades é algo vivo e em constante transformação, na obra Os alemães, Elias (1997) aborda as mudanças entre formalidade/informalidade a partir do século $X X$, com particular atenção para a questão geracional no que se refere à revisão dos comportamentos, antes tidos como adequados, entre indivíduos de classe social, gênero ou geração diferente. Como marca da diminuição das distâncias econômicas no pós-guerra, essas novas gerações pretendem também eliminar as barreiras que antes traduziam as distâncias sociais, evidentes nas variadas formas de tratamento e polidez dispensadas às pessoas hierarquicamente superiores nas relações em público. A moda, nesse sentido, é a parte visivel desse processo de relativo relaxamento do autocontrole e menor formalidade nas relações sociais que são mais visiveis a partir dos anos 1960.

Mas houve outro momento de grande evidência da juventude por meio do hedonismo: a década de 1920. Nos chamados "anos loucos", a moda e o comportamento 
da juventude bem nascida traduziam em imagens e cores os desejos de mudanças na estrutura da sociedade. 0 pós-Primeira Guerra Mundial viu nascer uma moda feminina relativamente sóbria, mais curta, celebrando um corpo novo, jovem e esportivo, livre dos constrangimentos do espartilho e da crinolina. Essa roupa mais leve para um corpo mais esguio e ágil era necessária, pois a dança se tornava uma diversão mais corrente e agora se dava ao ritmo do fox-trot e do jazz, o que impunha certa rapidez e frenesi aos movimentos dos jovens que, embora aos pares, dançavam separados na maior parte do tempo.

Talvez por essa razão as obras de Scott Fitzgerald sempre tenham sido tomadas como "retratos" dessa época. Um pouco como Balzac na Paris do século XIX, Fitzgerald também exerce esse papel de cronista, descrevendo sua geração. Seu mais conhecido romance, 0 grande Gatsby, de 1925, foi adaptado quatro vezes para o cinema: em 1926, ainda durante o cinema mudo; em 1949; a mítica e até pouco tempo a mais conhecida versão, em 1974, com Robert Redford no papel do milionário apaixonado, Mia Farrow como Daisy e figurinos em tons pastel de Ralph Laurent. A adaptação de 2013 de Baz Luhrmann, com figurinos ostensivos de Miuccia Prada, com o rap substituindo o jazz na trilha sonora, agradou a poucos, mas talvez tenha o mérito de mostrar esse clássico americano às novas gerações, considerando o apelo juvenil do astro Leonardo Di Caprio no papel de Gatsby.

\section{A juventude em Fitzgerald}

Como crônicas do período, no entanto, sua obra é reveladora tanto da rapidez do progresso econômico alcançado pelos Estados Unidos na década de 1920 quanto da inacessibilidade do "sonho americano" para todos, descrevendo ainda o tédio e os desejos de mudança da juventude dourada, embalados pelo ritmo frenético do jazz. Os versos de algumas músicas populares da época acompanham os personagens em determinados momentos da ação, conferindo um fundo musical às cenas descritas, dando a impressão, verdadeira ou não, de que a música estava em toda parte. Se pensarmos no papel da mulher burguesa na Nova York do final do século XIX e início do século $X X$, ela era praticamente um adorno da casa, tendo a beleza e a virtude como principais preocupações. Presa em suas roupas por meio do espartilho, o que dificultava a simples operação de se vestir sem ajuda, essa mulher é a demonstração da riqueza de seu possuidor (pai ou marido). Nos anos 1920, no entanto, vemos a muIher já no espaço público, fumando, dançando, sempre em movimento, dando a ideia de maior independência e atividade. 0 que Fitzgerald nos revela, todavia, é a sutileza dessa sociedade, que pode dar a impressão de grande mobilidade, de franco relaxamento dos costumes e de novos comportamentos, mas permanece quase exatamente a mesma retratada por Edith Warthon (2011) em A época da inocência.

Publicado em 1920, esse romance de Warthon retrata o período de 1870, conhecido como Guilded $\mathrm{Age}_{1}^{3}$ ou Idade do Ouro, quando os Estados Unidos viveram uma grande expansão econômica e populacional. Nessa época, uma elite enriquecida de industriais, banqueiros e comerciantes compunha a alta sociedade nova-iorquina, rivalizando-se nas demonstrações de riqueza e poder e vivendo sob regras de etiqueta e comportamento mais rígidas do que as aristocracias europeias. Tal sistema possibilita distinguir uma "genealogia do dinheiro", ou seja, as velhas e as novas fortunas, o prestígio dos herdeiros contra a sede de ascensão dos arrivistas (FOULKES, 2008).

A obra A época da inocência transmite as impressões de um passado particularmente rígido em relação às mulheres e às classes desprivilegiadas. Essa rigidez funcionava de forma muito sutil, podendo enganar o olhar desatento, mas a inflexibilidade logo se fazia sentir. No romance, a condessa Olenska vem para Nova York após se separar de seu marido, um conde russo com quem vivia na Europa. Ela pretende se divorciar e ser novamente acolhida por sua familia americana. Vale lembrar que uma mulher não precisava estar condenada a um casamento infeliz e podia perfeitamente divorciar-se, no entanto, estava fadada a uma vida discreta e ao isolamento social, não podendo frequentar festas, teatros, ópera ou qualquer outra reunião. Possivelmente isso encontra paralelo com a biografia da própria autora, que, após 28 anos de um casamento infeliz em Nova York, divorcia-se e vai morar em Paris, mais flexível naquele momento quanto à liberdade das mulheres. 
A obra de Fitzgerald celebra o otimismo e a riqueza americana do período. Já ao final do século XIX, os Estados Unidos eram um país que não apresentava áreas inexploradas, e as indústrias de base (aço, petróleo, eletricidade e transportes) encontravam-se implantadas e em plena expansão. Nesse momento, contudo, os americanos ainda não tinham consciência de sua grandeza. Após a Primeira Guerra Mundial, que inclusive ampliou os horizontes da economia americana, essa sociedade conheceu uma nova "era de ouro". Durante a década de 1920 e até o crack da Bolsa, em 1929, havia uma confiança no sucesso e no futuro ainda sem precedentes. Esse otimismo fez com que muitos imigrantes europeus se dirigissem ao país, assim como em épocas anteriores, dessa vez não apenas desejando, mas acreditando no enriquecimento. 0 grande Gatsby mostra que, atrás dos tecidos diáfanos e de cores suaves, gramados bem aparados e cascatas de champanhe, o lugar de cada um permanece o mesmo. Ainda se trata de uma sociedade em que os herdeiros têm lugar garantido e os recém-enriquecidos devem provar, a todo momento, seu direito de pertencimento.

Um "espírito dos tempos" da década de 1920 está fortemente presente nas festas - pela primeira vez, antes dos anos do rock ' $n$ ' roll, vemos tantos jovens dançando num ritmo tão acelerado. A mulher conta com um figurino mais apropriado para demonstrar sua desenvoltura nos salões da época. Os cortes de cabelo à la garçonne, a silhueta tubular e os seios achatados, tudo isso a rejuvenesce, encobrindo os atributos de fertilidade antes ressaltados. Em vez da maturidade fértil, temos a menina, a "melindrosa", a colegial festeira como ideal de beleza, efeito paralelo ao que veremos mais tarde, com Twiggy e a minissaia nos anos 1960. Se a mulher parece liberta da rigidez das regras do século anterior porque agora consegue se vestir sozinha, dirigir automóveis, praticar esportes e, eventualmente, trabalhar, Fitzgerald evidencia que essas aparências podem ser enganadoras.

\section{Os meandros de $O$ grande Gatsby}

A grande questão do casamento por contrato, claro, desapareceu, e as jovens dos romances de Fitzgerald escolhem ou concordam na escolha de seus maridos. Demonstram, no entanto, que a questão de classe e o "casamento seguro", que pressupõe um marido rico, não foram esquecidos. Em seu primeiro romance, Este lado do paraíso, Amory, estudante de Princeton e aspirante a escritor, mas ainda sem um futuro definido, conhece Rosalind, uma bela jovem irmã de um amigo e muito cortejada por outros jovens. 0 amor que dura todo um verão é interrompido por Rosalind, que, seguindo os conselhos de sua mãe, reconhece que o futuro ao lado de Amory seria desastroso e 0 amor não resistiria à falta de luxo - vestidos da moda, cabeleireiros, viagens, automóveis, serviçais bem treinados, enfim, tudo o que compunha a vida de uma flapper do período. 0 romantismo não parece ser suficiente para tantos sacrifícios, assim como aconteceu com o próprio autor em sua vida, quando, também estudante de Princeton, conheceu Zelda Sayre, por quem se apaixonou. 0 namoro foi rompido por Zelda, que ficou noiva de outro jovem, mais rico e promissor que Fitzgerald.

0 relativo sucesso alcançado com a publicação do romance, em 1920, permitiu finalmente que Fitzgerald se casasse com Zelda. Vale ressaltar que a dor do amor ferido pela falta de dinheiro foi tão forte que aparece em várias obras do autor - o "herói" sem dinheiro, a garota bonita, divertida e um tanto excêntrica, como a própria Zelda, e a ameaça de outro homem, rico e, por vezes, mais velho, ao sucesso do romance.

Da mesma forma, em 0 grande Gatsby, o ponto central é o triângulo amoroso. Narrado por um observador privilegiado, Nick, ex-estudante de Yale vindo do meio-oeste para trabalhar no mercado de ações em Nova York, vizinho de Gatsby, um milionário de origem misteriosa que de tempos em tempos dá grandes festas em sua mansão. Nick também é primo de Daisy, uma bela e rica garota que se casou com Tom, ex-jogador de Yale; moram numa grande residência num bairro sofisticado, próximo ao de Nick, este menos tradicional em termos de riqueza e elegância.

Entre essas localidades e a cidade de Nova York está o que o autor chama de "o monte de cinzas", um lugar esquecido pelo progresso e a riqueza, onde vivem George Wilson, que tem uma oficina mecânica, e sua mulher, Myrtle, amante de Tom. A Sra. Wilson perdeu todo o amor pelo marido alguns dias após o casamento, quando alguém bateu à porta para pegar de volta o terno com o qual ele se casou. A ideia do 
terno emprestado lhe pareceu uma enganação, como se a vestimenta (emprestada) fosse uma promessa do Sr. Wilson de uma vida que, afinal, não se realizaria. Ao decidir trair o marido com Tom, pensa: "Você não vai viver para sempre, você não vai viver para sempre" (FITZGERALD, 2007, p. 56), numa clara opção pelo desejo hedonista em lugar da observância da rigidez moral normalmente exigida pelo compromisso do casamento.

Gatsby foi namorado de Daisy enquanto estava num campo de treinamento, antes de partir para a guerra. Conforme destaca Hosbawm (1995), o uniforme despertava um fascínio nas moças e, além disso, permitia camuflar as diferenças de classe social, à medida que igualava as pessoas. Ao saber do casamento da namorada com outro homem, tudo o que Gatsby pretende é reconquistá-la, recuperar o que havia deixado antes de partir para a guerra, como se o tempo não houvesse passado, assim como pensavam muitos jovens dessa geração (VISCARDI, 2011).

Ao retornar para os Estados Unidos, o objetivo de Gatsby é enriquecer o mais rápido possível, pois sabe que Daisy, cuja voz "tem som de dinheiro", não abandonaria sua vida apenas por amor. No afã de impressioná-la, ele a convida a visitar sua casa, juntamente com seu primo. A descrição de Nick dá conta da mistura de estilos e objetos na casa, servindo mais à ostentação que propriamente traduzindo o gosto de seu possuidor:

No interior da casa, enquanto passeávamos por salões de música estilo Maria Antonieta e salões Restauração (...). Subimos, passamos pelos quartos de dormir em estilos de época embrulhados em sedas nas cores rosa e lavanda, vividas com flores frescas, através de quartos de vestir, salões de bilhar e banheiros com banheiras embutidas no piso (...) (FITZGERALD, 2007, p. 110).

Longe de revelar uma preferência estilística, a mansão de Gatsby se parece, nas palavras de Nick, mais com "uma feira mundial" e revela a intenção de cada objeto em impressionar os visitantes. A excursão de Daisy e Nick atinge seu ápice no quarto de dormir de Gatsby:

Recuperando-se num minuto, abriu para nós dois guarda-roupas gigantescos que continham a sua quantidade de ternos, roupões e gravatas, e suas camisas guardadas como tijolos em pilhas de doze.

"Tenho um homem na Inglaterra que compra roupas para mim. Ele me manda uma seleção de coisas no começo de cada estação, primavera e outono."

Tirou uma pilha de camisas e começou a arremessá-las uma a uma diante de nós, camisas de puro linho, de seda espessa e de fina flanela, que perdiam suas rugas ao cair e cobriam a mesa numa desordem multicolorida. Enquanto as admirávamos, ele pegou mais algumas e o monte macio e rico cresceu - camisas com listras, com arabescos, axadrezadas em coral e maçã, verde e lavanda e laranja-claro com monogramas em azul-da-índia (...) (FITZGERALD, 2007, p. 111).

Diferente daqueles que nasceram na riqueza e, portanto, estão perfeitamente seguros para expressar um estilo ou preferência, o milionário Gatsby revela sua posição de dominado em termos de capital cultural (BOURDIEU, 2004), pois segue a moda à risca, incapaz de perceber as incongruências em termos de estilo entre as várias propostas em voga. Elas funcionam como signo de poder econômico que pode esconder sua origem humilde e que o faz, segundo acredita, semelhante a um herdeiro rico ou um "homem de Oxford". Suas roupas claras, seu terno rosa, assim como os vestidos brancos e farfalhantes de Daisy e sua amiga Jordan, revelam a ociosidade dos ricos que podem exibir trajes imaculados, reforçando o caráter pouco prático de tais trajes para aqueles que trabalham. Também a Sra. Wilson acredita que as roupas podem mascarar sua realidade. Suas demonstrações de refinamento, a partir de atitudes arrogantes, coincidem com sua troca de roupas. Num momento em que as roupas já não apresentam a rigidez que impunha ao corpo os movimentos da boa educação, a 
personagem ainda atribui à moda essa capacidade. Quanto mais fino e caro o vestido, maior sua preocupação em mostrar-se à altura deles:

\begin{abstract}
A Sra. Wilson havia trocado a roupa um pouco antes e envergava agora um elaborado vestido de tarde, creme em gaze de seda, que provocava um farfalhar contínuo quando ela se deslocava pela sala. Com a influência do vestido, sua personalidade também sofrera uma mudança. A intensa vitalidade, tão notável na oficina, agora se convertera numa arrogância impressionante. Seu riso, seus gestos, suas declarações se tornavam mais violentamente afetados a cada momento e, à medida que se expandia, a sala se tornava menor em torno dela, até que parecia girar num eixo ruidoso e rangente pelo ar enfumaçado (FITZGERALD, 2007, p. 50).
\end{abstract}

Ao convidar pessoas ricas e célebres para suas festas, Gatsby tenta fazer uma transferência de prestígio, de tal maneira a atrair comentários e admiração. Apenas a riqueza não bastava para a concretização de seu plano, era necessário ser também aceito socialmente. A bravura demonstrada na guerra lhe rendeu uma patente respeitável para alguém tão jovem, muitas medalhas e a possibilidade de construir um passado honroso que pudesse justificar seu sucesso misterioso no presente. 0 personagem apenas flutua entre todos esses dilemas, pois nada importa mais que seu amor da juventude. As festas... os gastos excessivos... as cascatas de champanhe são, em tempos de prohibition, ${ }_{1}^{4}$ mais um símbolo de ostentação do que propriamente uma conduta transgressora e hedonista.

0 personagem de Nick situa-se num meio-termo entre a alta classe, à qual não pertence, e o vizinho arrivista Gatsby. Como este, Nick lutou na guerra e igualmente pretende alcançar sucesso em Nova York. Mas assim como Tom, formou-se em Yale, onde seu pai também estudou, e sua família é, há três gerações, conhecida e respeitada proprietária do comércio de ferragens em sua cidadezinha. Sua origem burguesa não faz dele propriamente um herdeiro econômico, mas ao menos é um herdeiro em termos de capital cultural. Passeia pelo mundo dos (muito) ricos, mas não pertence a ele, o que o faz, ao longo do romance, ir assumindo uma simpatia por Gatsby, ao mesmo tempo que revela a corrupção e deslealdade do mundo da upper class. Gatsby permanece um homem fiel ao amor da juventude, ao sonho de conquistá-lo, às suas responsabilidades, como o soldado que deve cumprir sua missão à despeito das consequências. A origem ilegal de seu dinheiro perde importância moral diante da injustiça de ter o acesso aos sonhos negado. 0 desfecho final revela a fidelidade de Daisy a uma classe social, incapaz de arcar com as consequências de seus atos.

Embora a riqueza das festas de Gatsby possa indicar a realização do american dream, ao final do romance, fica claro justamente o contrário. As bases de uma sociedade de classes fortemente ancorada na tradição e poder econômico ainda se fazem sentir e seguem passando por cima dos sonhos daqueles que tentam transpor suas barreiras. De outra parte, a juventude, ainda que possa gozar da diversão despreocupada característica daquele momento, ainda está subordinada às decisões dos adultos, verdadeiros donos do dinheiro. Será preciso esperar até a década de 1960 para que os jovens, desta vez não mais os representantes privilegiados de uma classe, mas como geração, conquistem uma liberdade mais sólida e duradoura. Essa liberdade juvenil atingirá, ao mesmo tempo, todos os grupos etários. 


\section{NOTAS}

${ }^{[1]}$ Sobre a abordagem da juventude antes dos anos 1950, veja: Bourdieu (1983), Perrot (1992) e Silva (2003). ${ }^{[2]}$ Outras de suas obras também foram adaptadas para o cinema, como Suave é a noite (romance de 1934), 0 último magnata (publicado postumamente em 1941), e os contos Babilônia revisitada e 0 curioso caso de Benjamin Button. Desperta atenção, até mesmo os anos finais de sua vida, quando amargava certa decadência trabalhando para Hollywood para sustentar as internações de sua ex-mulher Zelda, e se casou com a colunista Sheila Graham, com quem viveu seus últimos momentos, tema do filme O Ídolo de Cristal, estrelado por Gregory Peck e Deborak Kerr, em 1959.

${ }^{[3]} 0$ período de 1860 a 1890, ou seja, após a Guerra Civil americana e antes da crise de 1893, ficou conhecido como a Guilded Age, momento em que a antiga burguesia americana disputava prestígio com os "novos ricos". Muitos personagens do romance correspondem a pessoas da vida real daquela época. Ward McAllister, uma autoridade do periodo em termos de etiqueta, elegância ou genealogia das famílias nova-iorquinas, difundiu a ideia de que na Nova York do final do século XIX havia apenas 400 famílias realmente importantes a serem frequentadas. Aliado à Sra. Caroline Astor, elaboravam a exclusiva lista dos 400 nomes aptos a compor o seleto grupo de convidados ao baile anual da Grande Dame, a Sra. Astor. Para se aprofundar no estudo deste período, veja: Foulkes (2008).

${ }^{[4]}$ Trata-se da Lei Seca que vigorou nos Estados Unidos entre 1920 e 1933, símbolo da vitória dos movimentos religiosos e reformadores, como a Temperança. Essa lei proibia a produção, consumo e comercialização de bebida alcoólica.

\section{REFERÊNCIAS}

BOURDIEU, P. A "juventude" é apenas uma palavra. In: Questões de sociologia. Rio de Janeiro: Marco Zero, 1983, p. 112-121.

A economia das trocas simbólicas. São Paulo: Perspectiva, 2004.

ELIAS, N. O processo civilizador: uma história dos costumes. Rio de Janeiro: Jorge Zahar, 1994, v. 1. Os alemães. Rio de Janeiro: Jorge Zahar, 1997.

FITZGERALD, F. S. Babilônia revisitada. In: 24 Contos de F. Scott Fitzgerald. São Paulo:

. O grande Gatsby. Rio de Janeiro: Bestbolso, 2007.

Suave é a noite. Rio de Janeiro: Bestbolso, 2008.

0 curioso caso de Benjamin Button. São Paulo: Ediouro, 2009.

Este lado do paraíso. Rio de Janeiro: Bestbolso, 2011.

0 último magnata. Rio de Janeiro: Bestbolso, 2011.

FOULKES, N. High society: the history of America's upper class. Nova York: Assouline, 2008.

GROPPO, L. A. Uma onda mundial de revoltas: movimentos estudantis nos anos 1960. Campinas, 2000. Tese (Doutorado em Sociologia) - Instituto de Filosofia e Ciências Humanas, Universidade Estadual de Campinas.

HOBSBAWM, E. A era dos extremos: o breve século XX. São Paulo: Companhia das Letras, 1995.

LIPOVETSKY, G. 0 império do efêmero: a moda e seu destino nas sociedades modernas. São Paulo: Companhia das Letras, 2004.

PERROT, M. Os excluídos da história: operários, mulheres e prisioneiros. Rio de Janeiro: Paz e Terra, 1992.

RODRIGUES, N. O remador de Ben-Hur: confissões culturais. São Paulo: Companhia das Letras, 1996, p. 221.

SILVA, E. M. A violência diletante: um estudo das brigas juvenis no contexto do lazer. São Paulo, 2003. Tese (Doutorado em Ciências Sociais) - Pontifícia Universidade Católica de São Paulo.

. É possivel falar de tribos urbanas hoje? A moda e a cultura juvenil contemporânea. lara Revista de Moda, Cultura e Arte, São Paulo: Senac, v. 4, n. 1, p. 47-64, abr. 2011.

SIMMEL, G. Filosofia da moda e outros escritos. Lisboa: Texto \& Grafia, 2008.

VISCARDI, R. F. A posição do narrador em 'The Great Gatsby' de F. Scott Fitzgerald. São Paulo, 2011. Dissertação (Mestrado em Estudos Linguísticos e Literários em Inglês) - Faculdade de Filosofia, Letras e Ciências Humanas, Universidade de São Paulo.

WHARTON, E. A época da inocência. Rio de Janeiro: Bestbolso, 2011. 